\title{
Using Secondary Fish Raw Materials to Produce Gerodietic Food Products
}

\section{Elena N. Kharenko and Ekaterina S. Belomyttseva}

Federal State Budgetary Scientific Institution "Russian Federal Research Institute of Fisheries and Oceanography"

Abstract. Elderly people frequently experience a decrease in body weight, associated primarily with a decrease in protein intake, for a variety of reasons, including social factors. In this regard, the consumption of liquid food rations enriched with watersoluble protein hydrolysates is the simplest solution to the problem of providing people with sufficient protein intake. Development of methods for the manufacture of fish and cereal-based products is promising due to the possibility to simulate the composition of a certain nutritional compound for functional consumption by various population groups. Our task was to substantiate the parameters and components for creating a product for gerodietic use. The development of the technology included the following stages: preparation of ingredients, such as cereal filler, by-products from

Corresponding Author: Elena N. Kharenko; email:

harenko@vniro.ru

\section{Dates}

Published 13 January 2022

Publishing services provided by Knowledge E

(c) Elena N. Kharenko and Ekaterina S. Belomyttseva. This article is distributed under the terms of the

Attribution License, which permits unrestricted use and redistribution provided that the original author and source are credited.

Selection and Peer-review unde the responsibility of the 8th Scientific and Practical Conference Conference Committee. herring cutting, natural food coloring, vegetable oil, table salt and water; their mixing; heat treatment; cooling and packaging. The finished product has a light orange color, characteristic of natural pollock roe, and a pleasant fishy smell; the "fish eggs" are easily separated from each other. New types of gerodietic products make it possible to increase the nutritional and biological value of the diet of the elderly, as well as to inhibit the development of age-related pathological changes.

\section{Keywords: Secondary Raw Materials, Functional Foods, Gerodietic Food Products}

Rational nutrition of the elderly is one of the core issues brought up in the "State Policy of the Russian Federation in the Sphere of Healthy Nutrition", which takes into account the UN recommendations on the matter. Its successful implementation makes it possible to develop recommendations for increasing the working capacity of senior citizens and optimizing their lifestyle through further rationalization of nutrition.

When creating food products for the aging and the elderly, it is rather difficult to achieve a balanced chemical composition, if one relies solely on their natural reserves. The most promising solution to this problem is to implement the advantages of several key research areas.

Elderly people frequently experience a decrease in body weight, associated primarily with a decrease in protein intake, for a variety of reasons, including social factors. In this regard, the consumption of liquid food rations enriched with water-soluble protein hydrolysates is the simplest solution to the problem of providing people with sufficient protein intake. A decrease in the enzyme concentration observed among the elderly makes it impossible to fully assimilate proteins ingested with food. Some of them are 
absorbed, and some pass in transit, subjecting the digestive and excretory organs to an additional load; due to this, the protein entering the body need to be subjected to additional processing.

One way of protein degradation is hydrolysis, which results in the peptide bonds of a protein molecule breaking down into easily assimilated peptide fragments and amino acids. Compared to inactive protein, the period of absorption and assimilation of such a structurally altered protein with a high degree of specificity is significantly reduced.

\section{MATERIALS AND METHODS}

The product development concept was based on two main areas. The first is the utilization of presently discarded secondary fish raw materials. In our case, such raw materials include the ovarian fluid of sturgeon fish and herring offal. And the second is the creation of products for gerodietic purposes, which are clearly hard to find at the grocery store. It is rational to create products consumers would find familiar, but that are made from cheaper and more accessible raw materials. The objective was to obtain a fish and cereal-based product balanced across all dietary nutrients and suitable mainly for gerodietic purposes. Pollock roe, a product in high demand among consumers, but with restrictions on price and sales period due to a rather short ( 3 months a year) period of fishing for pollock with gonads of stage IV maturity, which are used to prepare screened caviar, was used as a substitute.

For the purposes of this study, standard and generally accepted research methods were used. Gathering of samples and their preparation for analysis was carried out in accordance with GOST 31339 and GOST 7636. Protein content was determined by the Kjeldahl method on automatic analyzers "Kjeltec-1003" and "Kjeltec-2300". The amino acid composition of proteins was analyzed by the method of quantitative ion exchange chromatography on an Aracus amino acid analyzer (membraPure, Germany). Lipid extraction was performed by the Bligh and Dyer method. Fatty acids in the form of methyl esters were analyzed on a Shimadzu GC-16A gas chromatograph (according to GOST 31663).

Secondary raw materials from cutting salted herring were an important component. According to our data, the process of carving out skinless fillets produces on average more than 50\% of waste products. [Kharenko, 2016]. Frozen Atlantic and Pacific herring defrosted and salted with mixed salt until its salt content reached up to $5.0 \%$, then cut into skinless fillets was used for the purposes of this research project. To obtain the 
hydrolyzate, skin, bones, heads without gills, trimming of muscle tissue and gonads were used.

To impart a caviar flavor to the product, a dry concentrate of ovarian fluid of sturgeon fish was used. Ovarian fluid in an accessible form for further processing is formed in the case of intravital production of sturgeon caviar fish. This method has become widespread in recent years, since it allows to preserve and use the female specimen for a long period of time. The sturgeon caviar obtained in such a manner is used both for fish breeding purposes and for the production of caviar products. One of the features of this type of raw material is the presence of amniotic fluid, i.e. ovarian fluid (OF). According to our data, the yield of fish eggs in the ovarian fluid amounts to $10-30 \%$ of the weight of female, depending on the type of fish, its size and mass characteristics and age, while the ovarian fluid constitutes 10 to $25 \%$ of the weight of eggs. [Kharenko, Sytova, 2011, 2012]

The study of the functional and technological properties showed that the OF is a semi-transparent finely dispersed colloidal system. The color ranges from light beige to slightly grayish and pinkish in case of blood vessel ingress. The content of dry matter is about $2 \%$, protein content ranges from 35.1 to $56.2 \%$ (in terms of dry matter), an insignificant content of fat $-0.07-0.10 \%$ and ash $-0.4-0,7 \%$ is revealed. The protein matrix of the OF consists of 19 amino acids, of which 8 are essential; their ratio to the total of nonessential amino acids is more than 0.96.A high content of lysine, threonine, methionine and histidine was noted. Aspartic acid, glutamic acid, alanine and serine are the dominant nonessential amino acids. A relatively high content of vitamin B1 (up to $3.5 \mathrm{mg} / 100 \mathrm{~g}$ ), as well as of macronutrients, in particular, such as $\mathrm{K}(21.5-48.3 \mathrm{mg}$ / $100 \mathrm{~g})$ and $\mathrm{Mg}(2.1$ - $3.2 \mathrm{mg} / 100 \mathrm{~g})$, was revealed.

In sturgeon fish products of aquacultural origin, it is necessary to control the residual amounts of GMI, which can enter the fish during feeding. We have determined that the ovarian fluid of sturgeon fish, such as the sterlet/bester hybrid and the Lena sturgeon, contains no genetically modified ingredients [Sytova, 2009].

The use of such unconventional secondary raw materials as ovarian fluid in various fields is promising; however, in its native state, this raw material is not fit to be used, due to active microbiological contamination during storage. Therefore, the OF was subjected to drying, which allowed, on the one hand, to increase storage capacity, and on the other hand, to concentrate biologically active substances. It has been found that spray drying is the most economical compared to vacuum infrared foam drying and freeze drying [Dmitrieva, 2012]. The dry concentrate was a medium-hygroscopic 
fine powder of a grayish-beige color, resembling flour in consistency, with a faint "fishy" smell, and readily soluble in water and saline.

\section{RESULTS AND DISCUSSION}

Development of methods for the manufacture of fish and cereal-based products is promising due to the possibility to simulate the composition of a certain nutritional compound for functional consumption by various population groups. For example, one method of obtaining such a fish and cereal-based product as pollock roe substitute includes preparation, dosage of cereal filler, fish waste, table salt, dye, water, vegetable oil, preparing a decoction of fish waste with the addition of table salt, dye, filtering the broth, adding cereal filler, cooking, cooling, introduction of vegetable oil. However, this method has its drawbacks. The shelf life of the product at temperatures from 0 to $5^{\circ} \mathrm{C}$ is only 3 days. [RF patent No. 2320223]. This analogue has no dietary purpose, since the ratio of proteins: fats: carbohydrates in this recipe is approximately 2.0: 2.5: 8.5, while the optimal ratio for dietary nutrition should be 1: $0.8: 3.5$ respectively. Therefore, our task was to substantiate the parameters and components for creating a product for gerodietic use.

The development of the technology included the following stages: preparation of ingredients, such as cereal filler, by-products from herring cutting, natural food coloring, vegetable oil, table salt and water; their mixing; heat treatment; cooling and packaging. Occasionally, spices and sturgeon OF were used as additional ingredients. The byproducts from cutting salted fish were homogenized; water was added to the resulting homogenized product, before it was sent to ultrasonic treatment at a frequency of 22 $44 \mathrm{kHz}$ for 5 - 15 minutes. After processing, tomato paste, salt and spices were added to the homogenized product, it was mixed and sent for hydrolysis at $t=18-20^{\circ} \mathrm{C}$ for 4 hours. The resulting hydrolyzate was filtered and a cereal filler was added in an amount of $10 \%$ [Kharenko, 2012]. Heat treatment was carried out by means of pasteurization of the mixture at a temperature of $85-90^{\circ} \mathrm{C}$ for $1-2$ minutes; after the mixture was cooled before packaging, vegetable oil and dry OF powder were added in an amount of 0.1$0.5 \%$ of the weight of the mixture [RF Patent No. 2467653].

The finished product has a light orange color, characteristic of natural pollock roe, and a pleasant fishy smell; the "fish eggs" are easily separated from each other. A gentle technological treatment, which makes it possible to maximally preserve the biologically active substances of the raw material, is used to preserve the targeted properties of the product. The product contains an optimal ratio of polyunsaturated fatty acids $\omega-6$ : 
w-3 PUFA - 5: 1, which conforms to the recommended standards for the aging and the elderly. At the same time, lycopene, an antioxidant contained in tomato paste, which simultaneously acts as an acidity regulator, is preserved. Pasteurization does not affect the nutritional value of products in any significant manner.

Adding sturgeon OF concentrate to the finished product in an amount of $0.1-0.5 \%$ of the weight of the mixture enhances the caviar flavor, as well as enriches it with macronutrients, especially $\mathrm{K}$ and $\mathrm{Mg}$, as well as vitamin B1. The impact of ultrasonic vibrations on the physicochemical processes occurring in raw materials, as well as the disinfection of water and raw materials that are impacted in such a manner, also make it possible to improve the quality of finished products and extend its shelf life up to 7 days in a hermetically sealed container at a temperature from 0 to $+5^{\circ} \mathrm{C}$.

The technology developed makes it possible to obtain, mainly for gerodietic purposes, a nutritionally balanced caviar substitute from the unused secondary fish raw materials.

New types of gerodietic products make it possible to increase the nutritional and biological value of the diet of the elderly, as well as to inhibit the development of age-related pathological changes.

\section{References}

[1] Sytova MV, Kharenko EN, Mikodina EV, Ganzha EV, Dmitrieva EA. Safety indicators and the content of genetically modified sources in the ovarian fluid of sturgeon fish.Rybprom, 2009;1:54-57.

[2] Kharenko EN, Dmitrieva EA, Sytova MV.Comparative analysis of the functional and technological properties of ovarian fluid of various species (breeds) of sturgeon fish.RybnoyeKhoziaystvo.2011;3:79-85.

[3] Kharenko EN, Dmitrieva EA, Sytova MV.Development of drying regimes for sturgeon caviar protein fluid. Storage and processing of agricultural raw materials.2012;3:1215.

[4] Kharenko EN, Sytova MV, Gritsenko EA. New raw material produced from living sturgeon fish. Biochemical characteristics, drying technologies, prospective use. Lambert Academic Publishing Saarbrucken; Moldova, Chisinau, 2012.

[5] Kharenko EN, Fomicheva LF, Sytova MV. Fish cutting handbook. Moscow: Russian Federal Research Institute of Fisheries and Oceanography; 2016.

[6] ShchepochkinaYA .RF patent No. 2320223. A method of obtaining artificial caviar. Moscow, Standartinform, 2008. 
[7] Kharenko EN, Ostrikova El. The use of ultrasonic processing to improve the quality of substitute products from secondary fish raw materials.RybnoyeKhoziaystvo.2012;5:109 -113

[8] Kharenko EN, Ostrikova El, Bedina LF.RF patent No. 2467653. A method of obtaining caviar substitute. Moscow, Standartinform, 2012. 